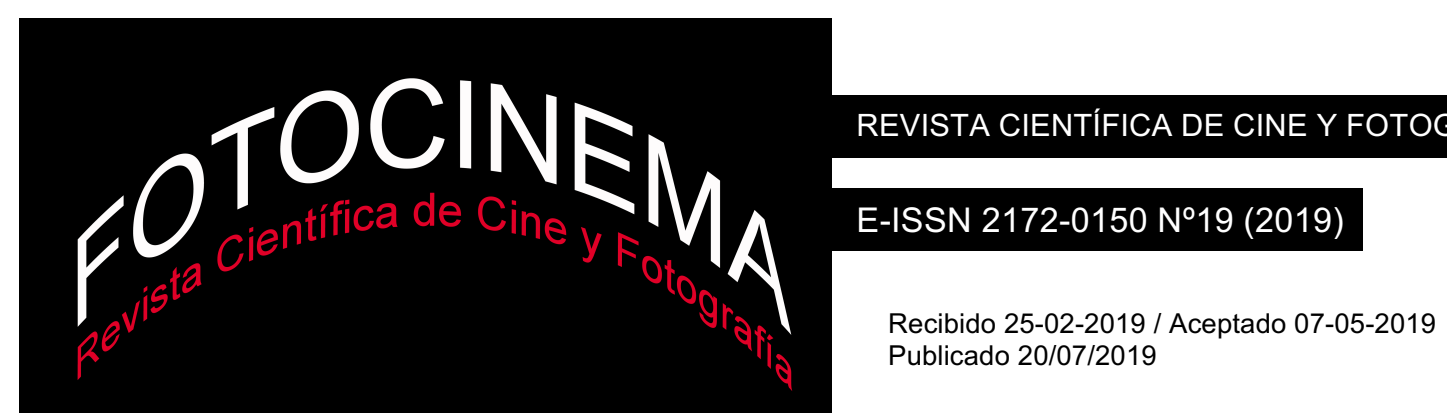

\title{
El cine de Mar Coll: herencias catalanas de Eric Rohmer
}

\section{The cinema of Mar Coll: catalan inheritances of Eric Rohmer}

\author{
Álvaro Martín Sanz \\ Universidad Carlos III de Madrid, España \\ Universitat Oberta de Catalunya, España \\ alvaromartinsanz@uoc.edu
}

\section{Resumen}

El presente artículo realiza un breve recorrido a través de la filmografía de Mar Coll, desconocida ganadora de un premio Goya como representante de toda una generación de cineastas catalanas mujeres que trabajando desde Barcelona luchan por salir de la invisibilidad. Así pues, se plantea un estudio del contenido narrativo de las obras que componen la filmografía de Mar Coll (La última polaroid, Tres días con la familia y Todos queremos lo mejor para ella) para, mediante un análisis comparativo de estas con las del cineasta de la Novelle Vague Eric Rohmer, ver cómo la influencia que la catalana recoge del francés acaba determinando las múltiples formas que caracterizan su estilo cinematográfico. Así, partiendo de un relato que se teje desde la sensibilidad de sus personajes, el cine de Coll conjuga toda una propuesta formal que se adapta a las circunstancias de los conflictos de su universo narrativo, creándose un estilo diferenciado caracterizado por toda una serie de planteamientos cinematográficos tanto recurrentes como reconocibles.

\begin{abstract}
This article makes a brief journey through the filmography of Mar Coll, unknown winner of a Goya award as the representative of an entire generation of Catalan women filmmakers who, working from Barcelona, struggle to emerge from invisibility. Thus, a study of the narrative content of the works that make up the filmography of Mar Coll (La última polaroid, Tres días con la familia y Todos queremos lo mejor para ella) is proposed through a comparative analysis of these with those of the filmmaker of the novelle vague Eric Rohmer, in order to see how the influence that Catalan picks up from the French ends up determining the multiple forms that characterize her cinematographic style. Thus, starting from a story that is woven from the sensitivity of his characters, the cinema of Coll combines a formal proposal that adapts to the circumstances of the conflicts of his narrative universe, creating a differentiated style characterized by a whole series of cinematographic approaches, both recurrent and recognizable.
\end{abstract}

Palabras clave:

Mar Coll; mujer; estudios de cine; Cataluña; Eric Rohmer; Nouvelle Vague.

Keywords:

Mar Coll; Women; Film Studies; Catalunya; Eric Rohmer; Nouvelle Vague. 


\section{Una cineasta catalana}

Una serie, producida por Movistar, dos películas, otros tantos cortos y multitud de premios y reconocimientos después, entre los que se encuentra el Goya a Mejor Dirección Novel en el año 2010, no han evitado que el nombre de Mar Coll sigue siendo desconocido para buena parte de los aficionados al cine, no digamos ya para el conjunto de la población de España. La escasa repercusión de la realizadora catalana puede explicarse como una consecuencia de un conjunto de causas entre las que estarían la invisibilización que ha sufrido tradicionalmente el cine de autor en nuestro país, la falta de consagración de su carrera (en comparación a otras directoras autorales como Icíar Bollaín o Isabel Coixet) o la dificultad para acceder a una buena producción y a un correcto circuito de distribución, dificultad en definitiva para levantar proyectos de presupuestos que podrían tildarse de normales en directores masculinos, una de las quejas más recurrentes entre las realizadoras españolas (Zurian, Pérez Sañudo, Vázquez Rodríguez, 2017, p. 36).

Lo cierto es que los elogios que ha levantado la realizadora por parte de la prensa especializada, trazando un estilo propio en un cine pausado, lírico y de diálogos, la han llevado a ser considerada como una de esas autoras poseedoras de lo que se denomina "universo propio" a pesar de una escasa filmografía, en la que, cabe aclarar, no entra de momento encargo alguno. Tan solo un cine en el que ejecuta desde sus inicios en su cortometraje $L a$ última polaroid (Mar Coll, 2004), el papel de creadora total, escribiendo y dirigiendo sus obras. Graduada en dirección por la ESCAC (Escuela Superior de Cine y Audiovisuales de Cataluña) deja bien claro con su mencionado proyecto la factura del cine que la interesa. Un cortometraje completamente alejado de los arquetipos de género fantástico que vienen desarrollándose tradicionalmente en el seno de la escuela y que obtuvo el Premio Nova Autoría a la Mejor Dirección en su estreno en el Festival de Sitges. Tan sólo una pequeña obra intimista de diecinueve minutos de duración en la que se exploran las estructuras, el tono, los temas y las formas que seguirá 
desarrollando en sus siguientes películas. Una trama en apariencia simple, la última noche previa a la separación de dos amigas adolescentes por el traslado de la familia de una de ellas de Barcelona a Málaga, le sirve a la directora para explorar todo un conjunto de relaciones y sentimientos que tan sólo quedan esbozados en pantalla, situándose su total expresión en la metanarrativa de un guion sin giros ni sorpresas. Tal y como sostiene Giulia Colaizzi:

El sino de un individuo en un microcosmos de relaciones, especialmente afectivas, cuyas vivencias son puestas en escenas en una estructura narrativa con final abierto como tranche de vie, es un nudo temático-formal fundamental en la obra de Mar Coll. (2017, p. 116)

Un espacio temático que se abre en torno al individuo que seguirá abordando en sus siguientes obras. Centrándose la narrativa de sus guiones, siempre escritos por la cineasta, en el acompañamiento del protagonista de cada film, que de esta manera queda radiografiado a medida que avanza la historia. Una temática que, como veremos, está también presente en una de las principales influencias de Coll, el realizador francés Eric Rohmer, cuyas películas se centran en las "confusiones y autoengaños de hombres y mujeres jóvenes y educados que se han dado cuenta de que "la vida real es siempre irreal, siempre imposible, en medio de la vida empírica" (Tester, 2008, p. 3)1. Así pues, el presente artículo plantea un estudio del contenido narrativo de las obras que componen la filmografía de Mar Coll para, mediante un análisis comparativo de estas con las del cineasta de la novelle vague Eric Rohmer, ver cómo la influencia que la catalana recoge, directa o indirectamente, del francés, acaba determinando las múltiples formas que caracterizan su estilo cinematográfico. Conjugando una mirada autoral por medio de unos planteamientos cinematográficos recurrentes y reconocibles.

${ }^{1}$ Confusions and self-deceptions of young(ish) educated men and women who have realised that 'Real life is always unreal, always impossible, in the midst of empirical life (Tester, 2008, p. 3). 


\section{Desde Barcelona con amor. Un cine de sensibilidad}

Más allá de los rasgos anteriormente señalados, también se aprecia en su primera obra una voluntad de localizar geográficamente la acción en Barcelona. Y es que la Ciudad Condal, más o menos reconocible ${ }^{2}$, va a encontrar de forma recurrente un hueco como telón de fondo de sus historias. De la misma manera muchos otros escenarios van a estar fijados en Cataluña, Girona por ejemplo como centro de acción de Tres días con la familia (Tres dies amb la família, Mar Coll, 2009). Elecciones que junto al uso del catalán como idioma predominante en sus filmes la convierten en una de las máximas exponentes del cine propiamente catalán. Así pues, si hablamos de cineastas barcelonesas de renombre, mientras que Isabel Coixet hace ya tiempo que se volvió una directora internacional, la ganadora del Goya The Bookshop (Isabel Coixet, 2017) como última confirmación, y María Ripoll parece sumergida en un cine de mayor o menor encargo de corte transnacional (Cordero Sánchez, 2017, p. 238), Coll parece seguir una dinámica territorial más marcada en la cotidianeidad cultural y geográfica en la que ha vivido desde joven. Cediendo tan solo la concesión de la lengua por lógicas razones de distribución del vídeo bajo demanda en su última miniserie, Matar al padre (Mar Coll, 2018), que aún con todo logra una perfecta ambientación de la ciudad de Barcelona en cuatro épocas distintas, desde la euforia posolímpica hasta la más reciente crisis económica.

Coll representa por lo tanto una de las últimas exponentes de un cine que, siguiendo a Cami-Vela, puede conectarse directamente con el de la generación de directoras catalanas que emergió a principios de los años 9o, una época en la que

Tras un siglo de marginalización en la industria cinematográfica [...] se caracteriza por el derecho reivindicativo de las mujeres a ponerse detrás de una cámara en busca de una voz y una mirada propia. Las directoras salen con

\footnotetext{
$2 \mathrm{Al}$ ser preguntada sobre la elección de situar en Barcelona su película Todos queremos lo mejor para ella (2013), Coll responde: "Pasa en Barcelona, pero tampoco es súper reconocible... hemos creado una atmósfera bastante gris, y por las calles y los edificios que salen... casi podría parecer París”. (Ribes, 2013)
} 
sus cámaras a las calles barcelonesas para crear un espacio cinematográfico que rechaza las relaciones de poder patriarcales (Cami-Vela, 214, p. 32).

Un resurgimiento de una serie de cineastas que pertenecen a lo que Carlos Losilla denomina "el otro cine español" (Losilla, 2013, p. 7), y que de nuevo en palabras de Cami-Vela dada la conexión con Barcelona y con sus instituciones educativas debiera llamarse el “otro cine catalán”. Sin ir más lejos, de los 52 realizadores considerados por Caimán Cuadernos de Cine 3 como pertenecientes a esta nueva corriente de cine español tan sólo hay ocho mujeres, Mar Coll, Cristina Diz, Virginia García del Pino, Mia de Ribot, María Ruido, Carla Subirana y Neus Ballús. Todas catalanas, con la excepción de María Ruido, gallega también establecida en Barcelona (Cami-Vela, 2014, p. 42). Siguiendo a Losilla:

Tengo la impresión de que este sentido de la comunidad cinematográfica nació con el regreso del exilio de una figura fundamental, la de Joaquín Jordá, a principios de los años noventa. Ya entonces Jordi Balló, desde la dirección del Máster de Documental de Creación de la Universitat Pompeu Fabra, reunió a diversas generaciones: el propio Jordá, pero también Jose Luis Guerin, los debutantes Isaki Lacuesta y Mercedes Álvarez, Ricardo Íscar y tantos otros que ahora culminan en figuras como Carla Subirana, Neus Ballús o Cristina Diz. Igualmente, desde la Universitat Autónoma de Barcelona, el Máster en Documental Creativo de Josep María Català y Josetxo Cerdán (luego director de Punto de Vista) supuso una cantera de la que han surgido tantos hombres y mujeres como ideas. Poco a poco, los críticos se convertían en profesores y los alumnos en cineastas. Surgía una cierta idea del cine (Cami-Vela, 214, p. 41).

Lo cierto es que este surgimiento de las cineastas catalanas se debe no solo al buen trabajo realizado desde Instituciones académicas como las citadas por Losilla o a la mencionada anteriormente ESCAC, que a través de Escándalo Films produce las películas de Coll, sino también a una política de apoyo institucional promovida desde la Generalitat de Catalunya que tiene también su reflejo en la participación de $\mathrm{TV}_{3}$ en las producciones realizadas en la región. Dos factores que promueven una idea de una cierta industria y que se

\footnotetext{
3 Puede consultarse la lista íntegra en: https://www.caimanediciones.es/los-nombres-deeste-nuevo-otro-cine-espanol/
} 
encuentran a años luz de las ayudas cinematográficas de otras Comunidades Autónomas como por ejemplo Castilla y León o Extremadura, en donde la producción audiovisual (tanto de mujeres como de hombres) es prácticamente inexistente, limitándose por lo general a cortometrajes sin salida comercial.

\section{El universo narrativo de la filmografía de Mar Coll}

Una de las principales características que tienen los universos narrativos de Coll es la toma de partido por un punto de vista femenino. Al ser preguntada sobre la importancia de los personajes femeninos en sus obras, y de que estos sean los absolutos protagonistas de sus cintas (al menos hasta el estreno de Matar al padre), a diferencia de las narrativas creadas por otros cineastas, Coll respondía lo siguiente:

Quizás el tema de los personajes femeninos no se ve mucho porque no hay mucha representación femenina. Obviamente si hubiera una situación más equiparada se vería más. Y me sale de una forma completamente natural, no tiene nada de reivindicativo. Simplemente cuando escribo me proyecto en el personaje, en la protagonista, de alguna u otra manera, pues claro, obviamente me es más fácil proyectarme en una mujer que en un hombre. Pero me interesa también... Ahora quizás me interesaría meterme en la piel de un tío porque si me parece también un mundo interesante (Martín Sanz, 2013).

Lo cierto es que las particularidades de los esquemas narrativos de su filmografía en cuanto a temas, situaciones y perspectivas encajan a la perfección dentro de la categoría definida por Mary Ann Doane como "cine de mujeres", formada por:

Filmes con protagonistas femeninas, centrados en la experiencia subjetiva de la mujer, con gran presencia de temas sociales y tintes melodramáticos, filmes en los que las espectadoras son invitadas a verse a sí mismas de manera compleja, más allá de los estereotipos tradicionalmente impuestos por el cine dirigido por hombres, y que por tanto generan mecanismos de identificación diferentes (Zurian, Pérez Sañudo, Vázquez Rodríguez, 2017, p. 36). 
Identificación que surge desde el planteamiento inicial de sus películas, posicionando al espectador del lado de un personaje femenino sumergido desde el inicio en un conflicto del que durante el desarrollo del metraje no vamos a presenciar más que cómo reacciona dicho personaje a él, y cómo busca la resolución en una etapa de metamorfosis y evolución. En el caso de la mencionada anteriormente La última polaroid, la realizadora nos trae de vuelta a nuestra infancia, mostrando los sentimientos y emociones de esas dos amigas del alma para las que su universo afectivo se resume prácticamente en la compañera de la que deben despedirse, sin duda el miembro más importante de una familia elegida. En frente el horizonte de la soledad visto desde una trágica perspectiva adolescente en donde no queda nada más que la máquina polaroid como fabricadora de nostalgias que regala esa última polaroid mencionada en el título de la obra. Y es que, citando a la pensadora americana Susan Sontag:

Cuando sentimos miedo, disparamos. Pero cuando sentimos nostalgia, hacemos fotos. [...] Todas las fotografías son memento mori. Hacer una fotografía es participar de la mortalidad, vulnerabilidad, mutabilidad de otra persona o cosa. Precisamente porque seccionan un momento y lo congelan, todas las fotografías atestiguan la despiadada disolución del tiempo (Sontag, 2011, p. 25).

Sobre el cine de Coll señala Irene Otero que:

La familia es la obsesión principal de su filmografía, que transita entre la nouvelle vague y el Woody Allen de Interiores (Interiors, 1978) o Septiembre (September, 1987), glocalizada en la alta burguesía catalana a la que pertenece la cineasta (Otero, 2017).

En consonancia con ello, la muerte del patriarca de una familia de clase media alta pone en marcha los mecanismos narrativos en Tres días con la familia, al tener la joven Léa que regresar desde Francia a Gerona para asistir al velatorio y al funeral de su abuelo. Se produce así con encuentro con la extrañeza y la otredad de una emigrada que de súbito vuelve a su casa para encontrar toda una serie de sentimientos encontrados con familiares y antiguos amigos. Siempre manteniendo un juego de apariencias en el que los problemas emocionales no se hacen explícitos por conveniencia, afectando 
directamente a los sentimientos de la protagonista de la historia, mostrados estos más en lo que calla que en lo que dice. Tal y como señala su directora:

Las relaciones familiares nos condicionan a nosotros como individuos, son las más complejas que existen. De por sí tienes un componente de conflicto; las relaciones paterno filiales, por ejemplo, nunca son limpias del todo. Siempre estamos que si mi madre me raya, que si hacen más caso a mi hermano que a mí... Es muy interesante observar cómo nos comportamos con el tema de la familia, porque son relaciones desde que naces y tú las acoges desde el principio, no desde la edad madura. [...]Lo bueno que tiene el tema de la familia, además, es que el espectador hace una identificación inmediata con su propia experiencia, establece comparaciones... Le llevas a realizar una reflexión personal, que es lo que yo quiero. Con la película planteamos qué es la familia hoy en día en Catalunya, cómo lo llevamos, qué podemos hacer con ello... (Filmin, 2009).

Esta convención en las relaciones familiares acaba desarrollando en determinados momentos un retrato de la hipocresía del trato familiar, a pesar de que la realizadora no quiera utilizar dicho término:

no hablaría de hipocresía porque me parece que el término encierra una cierta maldad y una intención, más bien se trata de que los personajes quieren hacer ver que todo está bien, que nada funciona mal. Hablaría de pudor, en este sentido, más que de hipocresía (Ibídem).

Esta tensión y juego de apariencias en las relaciones, si bien no llega al extremo de violencia y perturbación plasmado por Vinterberg en Celebración (Festen, 1998), dista mucho de ser inocua. Guiando las elecciones de la protagonista hacia la necesidad de un cambio en su vida que aligere la tensión que siente. Un cambio definido por la incertidumbre en el futuro próximo y en los propios sentimientos, "no lo sé" responde la protagonista a su padre al final de la obra. Una película que:

trata de una crisis y de una transformación no elegidas, sino sufridas, más la lógica narrativa y formal del texto -la poética visual que Mar Coll nos propone- nos remite, con decisión, una y otra vez, a los límites de la representación, que son también los límites del sujeto como sujeto agente/actor, que tiene que aceptar la pérdida para (re)articularse en su 
propia singularidad histórica y buscar así su propia, específica, forma de agenciamiento. (Colaizzi, 2017, p. 120)

La siguiente obra de Coll plantea de nuevo una crisis no elegida con una transformación necesaria como única salida posible para su protagonista. En Todos queremos lo mejor para ella (Tots volem el millor per a ella, 2013), seguimos la historia de a través de los ojos de Geni, una mujer en edad de madurez, superviviente de un accidente de tráfico que le ha dejado una secuela importante, una doble fisura: por un lado, física, una rodilla rota que le funciona mal y que la provoca una cojera que durará toda la cinta, y por el otro emocional, pues es a partir del accidente cuando la protagonista toma consciencia de las particularidades de su vida desde una inflamación emocional, con planes de futuro rotos, promesas incumplidas o sueños frustrados. El accidente, desencadenante de la trama que de nuevo queda fuera de la cinta, va a ejercer la función de catalizador, provocando sus consecuencias ciertos sentimientos que plantean la necesidad de un renacer que aporte cambio. Sensaciones que se acrecientan en la protagonista con el reencuentro de una antigua amiga de la infancia, quien al contrario que Geni, sí que ha logrado tener el estilo de vida que había planeado tener. En frente quedan las sensaciones del personaje interpretado por una excepcional Nora Navas, que busca en medio de situaciones incómodas de nuevo en el seno de una sociedad burguesa dominada por una hipócrita serie de convenciones que ahora sí dejan espacio al humor, culminar la dolorosa catarsis que la lleve a readaptarse a la esfera social.

El cambio final, la adaptación a la nueva vida que ahora sí comienza, queda de nuevo fuera de la película, retratada con decisión fugaz pero no precipitada, seguida de una desaparición instantánea y una búsqueda inútil que culmina en forma de travelling lateral. Una escena más bien propia de un universo woodyallenesco, con un dramático toque cómico y canción de jazz incluida, que propone la ruptura total con el personaje de Geni que se ha mostrado durante toda la cinta. Su desaparición equivale a su muerte, y a su vez, al nacimiento de un nuevo personaje que desaparece en su ruptura con los principales rasgos que lo definían. 
Así pues, los tres ejemplos señalados colocan en el centro del interés a una mujer frente al cambio en un determinado momento de su vida: Juventud (La última polaroid), postadolescencia (Tres días con la familia) y madurez (Todos queremos lo mejor para ella). Realizando una radiografía de un personaje femenino, que podría ser el mismo en los tres casos en distintos momentos de la vida, frente a un sistema externo de convenciones, obligaciones y apariencias ante el que solo puede adaptarse mediante un cambio personal que implique una transformación. Sin embargo, los principales golpes narrativos que desencadenan la acción (la muerte del abuelo, el accidente de Geni), no figuran en la trama más que como elementos presentes en el fondo, temas recurrentes que, a pesar de hilar la narrativa, quedan fuera de la escena. Y es que a Coll parece interesarle más el proceso sentimental que provocan estos momentos de ruptura, así como la evolución posterior que el personaje decide tomar. Lejos de mostrar arquetipos estables durante toda su obra, la construcción inicial de sus personajes dura poco en pantalla, deshaciéndose por medio del conjunto de elecciones que estos van tomando en el intento de la nueva elaboración de su identidad, la cual no se termina de completar nunca en la historia presentada.

\section{Reminiscencias del cine de Rohmer. Un cine de la palabra y los sentimientos}

Si bien es cierto tal y como hemos podido ver, la alargada influencia de Cataluña posee dentro de la obra de Mar Coll, a través de la presencia de distintos escenarios y personajes catalanes dentro de sus películas, no menos cierta es la influencia proveniente del país vecino al otro lado de los Pirineos. Estudiante egresada del Liceo Francés de Barcelona, las referencias al país galo se explicitan en algunos detalles de sus construcciones narrativas. "Hay una influencia de todo lo francés en mi vida, por la educación, por la proximidad... y no me importa hacer una referencia explícita a que esto existe" (Ribes, 2013). Así, Mientras que en Tres días con la familia la protagonista llega al funeral de su abuelo desde Francia, en donde vive con su 
pareja, en Todos queremos lo mejor para ella, como parte de su nueva vida, Geni se plantea volver a estudiar francés, además, el propio Liceu Francès se convierte en escenario de una secuencia.

Sin embargo, esta influencia francesa va más allá de una serie de referencias medidas y calculadas. Integrándose en su obra de una manera más profunda, dotando a sus películas, desde su concepción inicial en el guion, de una serie de características tanto estilísticas como formales que han provocado que no pocos críticos cinematográficos hayan visto en la joven realizadora catalana una heredera del cine de la Nouvelle Vague gracias a sus reminiscencias. Cabe recordar que este movimiento, surgido en el seno de la revista francesa Cahiers du Cinéma como respuesta al cine "oficial" del momento, se caracteriza desde sus inicios como una ruptura frente a la institucionalización del séptimo arte, posicionando al director como autor total de la obra:

La relevancia del autor enmarcaba la idea del filme como acto de discurso, como espacio narrativo y formal de expresión de un yo, introduciendo así un aspecto básico de la modernidad cinematográfica: la preeminencia de los aspectos discursivos sobre la restitución de una historia narrada desde su exterior; o, dicho de otro modo, la valoración de la opacidad fílmica como un valor antepuesto a la transparencia y verosimilitud inherentes al cine clásico. (Monterde, 2004, p. 15)

Se comienza a crear así un cine rompedor y personal que busca, en sus muchas y variadas formas, revolverse contra la tradición (Cousins, 2011) desde la subjetividad del autor. Célebres son las palabras de uno de los padres del movimiento, François Truffaut sobre las películas del mañana,

La película del mañana me parece aún más personal que una novela individual y autobiográfica, como una confesión o un diario. Los jóvenes cineastas se expresarán en primera persona y nos contarán lo que les sucedió y eso [...] casi siempre gustará porque será verdadero y nuevo ... La película del mañana será un acto de amor. (2007, p.33)4.

4 Le film de demain m'apparaît donc plus personnel encore qu'un roman individuel et autobiographique, comme une confession ou comme un journal intime. Les jeunes cinéastes s'exprimeront à la première personne et nous raconteront ce qui leur est arrivé [...] et cela 
Así pues, no pocos críticos han trazado puentes entre algunos de los cineastas de este movimiento y la creadora catalana. Sobre Tres días con la familia dice Jordi Costa: "Bastan pocos minutos de metraje para intuir en la mirada de Mar Coll una inclinación afrancesada, en el mejor sentido de la palabra” (Costa, 2009), especificando Fernando Méndez Leite que la película "bebe en las fuentes del cine francés actual (Assayas, Téchiné, Despleschin...) y que recuerda remotamente a momentos del gran Sautet" (Ribes, 2013). Mientras que de Todos queremos lo mejor para ella escribe Carlos F. Heredero que "a veces parece resucitar lejanos ecos de la Nouvelle Vague francesa" (Heredero, 2014). A propósito de estos y otros muchos comentarios del estilo con el estreno de su segunda película la realizadora catalana respondía lo siguiente: "Lo del cine francés y Rohmer lo repitieron mucho con la primera película, creo que tiene que ver con lo que te comentaba de buscar un cine más abierto, más reflexivo y menos emocional... o que busque la emoción por otros lados” (Ribes, 2013).

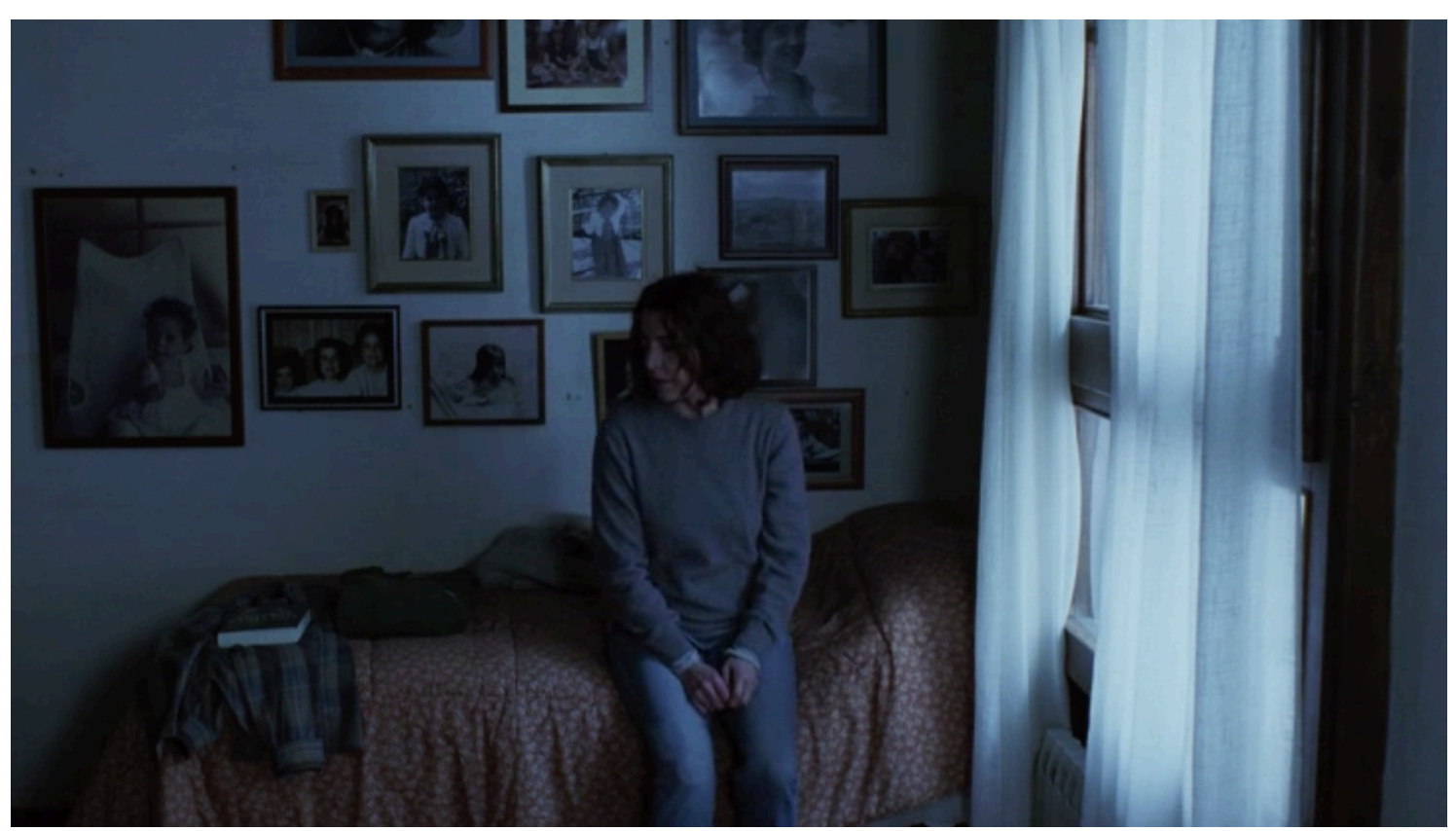

F1. Fotograma de Todos queremos lo mejor para ella (Mar Coll, 2013)

plaira presque forcément parce que ce sera vrai et neuf... Le film de demain sera un acte d'amour. (Truffaut, 2007, p.33) 


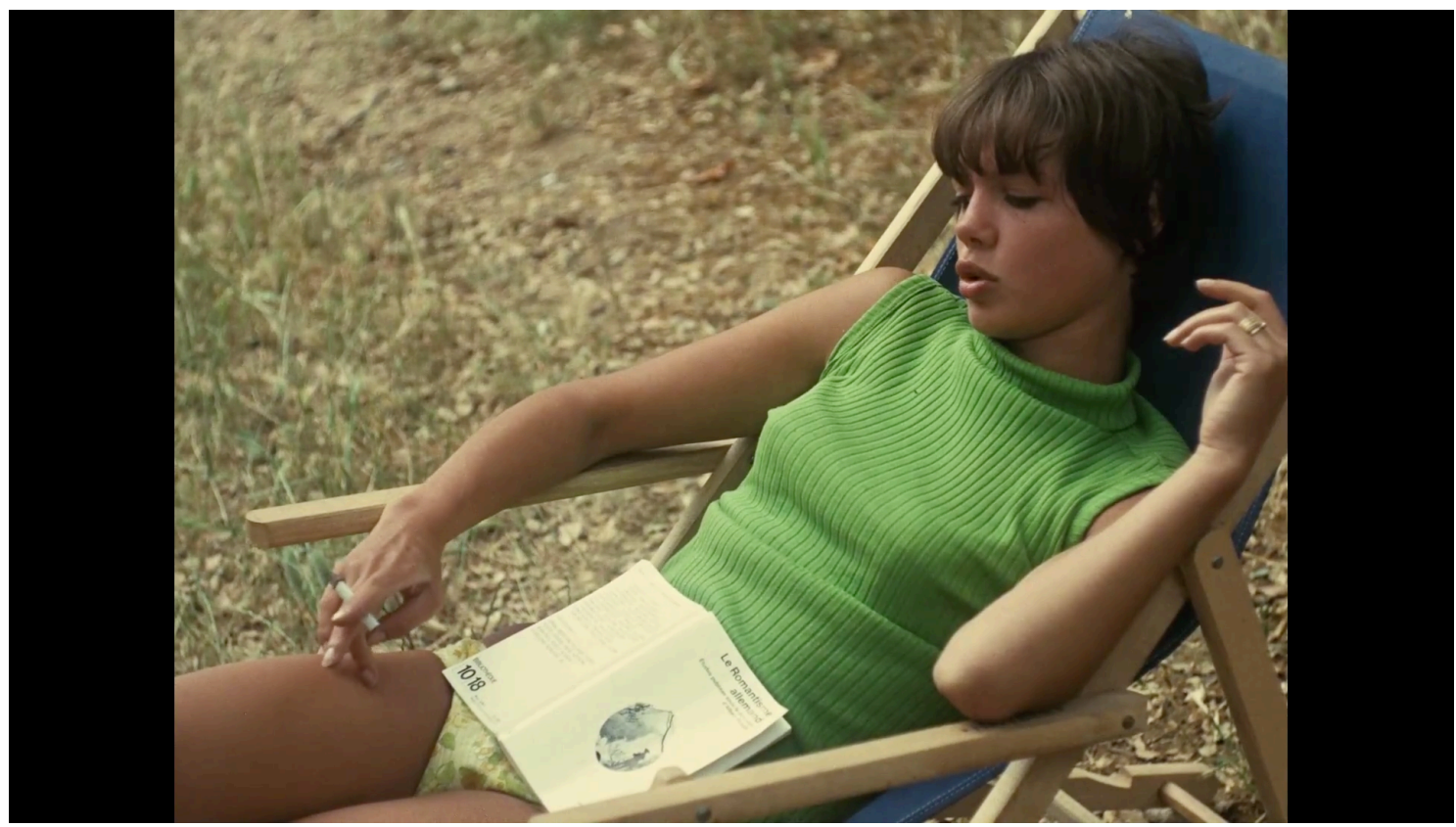

F2. Fotograma de La coleccionista (Eric Rohmer, 1967)

Lo cierto es que el admitir las cualidades de abierto y reflexivo es admitir una cierta concepción del cine que la acerca como ella bien dice al realizador francés Eric Rohmer. Y es que no pocas similitudes en cuanto a la temática unen la todavía breve filmografía de la directora catalana con la larga colección de obras filmadas por el cineasta de la Nouvelle Vague, ambos dos creadores de complejos universos narrativos que lejos de pretender simplificar la realidad y reducir a los personajes a típicos arquetipos maniqueístas, buscan elaborar un complejo mapa de los sentimientos que los mueven a realizar las acciones que hacen avanzar la trama. La palabra va a ser el vehículo que va a conducir estos sentimientos en todo momento.

Es necesario encontrar el medio de integrar la palabra no en el interior del mundo filmado, sino en el interior de la película, tanto si se trata del plano en el que se pronuncia como si se trata de la secuencia anterior o la siguiente. [...] Podemos centrar nuestra atención en el problema esencial: escribir diálogos hechos verdaderamente para la película en la que han de colocarse, lo que supone, por parte del dialoguista, un conocimiento perfecto del lenguaje visual por medio del que el realizador se quiere expresar y, por parte de éste -sino se trata, como sería de desear de una sola y única persona-, la voluntad de considerar la palabra como parte integrante de su obra. (Rohmer, 2000, p. 5456) 
Palabra que en no pocas ocasiones se va a encargar de configurar, en ambos cineastas una serie de retratos de la clase burguesa. Hipócrita, llena de falsas convenciones, y con un estilo de vida completamente opuesto al que aspiran a llevar los personajes principales. Rasgos de personalidad que ambos directores van a desvelar a través del lenguaje, siendo los diálogos (así como los silencios) que unos personajes mantienen con otros, la fuente a través de la cual el espectador va a poder comenzar a descifrar el complejo puzle que está armado detrás. Dicen Carlos Heredero y Antonio Santamarina al respecto del cine del director francés que:

La propuesta consiste en la contemplación y la reflexión sobre unos personajes sorprendidos en el ejercicio del lenguaje. Las películas no tratan de aquello sobre lo que se habla ni sus temas residen en las polémicas discusiones que a veces mantienen sus protagonistas. Los personajes de Rohmer no son hombres y mujeres de acción (como sí lo son los personajes de su admirado Howard Hawks), sino hombres y mujeres que hablan (Heredero, Santamaría, 2010, p. 92).

Esta ausencia de acción que caracteriza a sus personajes está sustentada por medio de un universo narrativo que, si bien está rígidamente estructurado, no contiene grandes elementos dramáticos. Así, siguiendo la idea de Rohmer de que "Todavía me considero un cineasta hitchcockiano" (Cardullo, 2012; Leigh, 2012, p. Ix)5 añade Jacob Leigh que "a lo largo de su carrera, Rohmer utiliza la conspiración de Hitchcock, aunque elimina los asesinatos y transpone las investigaciones, los misterios, el espionaje y el suspenso a los entornos ordinarios" (Leigh, 2012, p. Ix) ${ }^{6}$.

Así, la propuesta del universo narrativo va a estar en torno al relato hablado en el que se van a ir descubriendo los personajes. Característica esta que se emparenta directamente con las conversaciones que tienen lugar en las películas de Coll, en las que no pocas veces lo importante no son los diálogos explícitos, sino todo un conjunto de gestos que esconden emociones y sentimientos que reflejan el sentido y significado narrativos de cada escena.

5 I still consider myself to be a Hitchcockian filmmaker (Cardullo, 2012; Leigh, 2012, p. ix).

6 Throughout his career, Rohmer uses Hitchcockian plotting, though he removes the murders and transposes the investigations, mysteries, spying and suspense to ordinary settings (Leigh, 2012, p. ix). 
Avanzando la trama gracias a estos momentos, pues tal y como sostiene el profesor Gómez Tarín,

si hay discurso hay acto de habla, una enunciación, alguien que cuenta, lo que configura un protocolo narrativo, aunque pueda estar disimulado, y todo discurso integra una sucesión de acontecimientos, una historia que implica tiempo, acciones, y relación cronológica y lógica entre esas acciones (relaciones causa - efecto). (Gómez Tarín, 2006, p. 68)

Valgan como ejemplos las conversaciones que mantienen el personaje de Léa con su padre, interpretado por Eduard Fernández en Tres días con la familia, o esas que tiene el personaje interpretado por Nora Navas con su pareja en Todos queremos lo mejor para ella. Juego que se amplía con incontables matices cuando entran más personajes en escena en secuencias que plantean reuniones sociales de cualquier tipo en las que rigen distintas convenciones, un velatorio, un aniversario, una cena o una reunión de trabajo entre otras. Es en estas escenas en las que se reafirma la apuesta por la parcialidad que realizan ambos directores, quienes centran sus obras en unos personajes que las recorren de forma individual en oposición al resto como un todo que apenas es decodificado. En consonancia con Giulia Colaizzi, en las películas de Mar Coll, "tanto la dimensión escópica del texto, como la narrativa rehúsan articular y presentarnos el sentido como totalidad, y nos sitúan, en tanto espectadores, en la parcialidad” (Colaizzi, 2017, p. 117). Enlazando con lo expresado en el punto anterior acerca de la elección que toma Coll de plasmar a sus personajes protagonistas en tiempos de transformación, los relatos de ambos directores se centran en seguir a un único sujeto en un determinado periodo de cambio de su vida. No habiendo por lo tanto tanta diferencia entre los personajes femeninos de Coll, y los seres, tanto hombres como mujeres, que protagonizan distintos ciclos de obras del francés como los Seis cuentos morales, las Comedias y proverbios, o los Cuentos de las cuatro estaciones, definidos por Gubern como un cine de los sentimientos y de la intimidad (Gubern, 2014, p. 552).

Este seguimiento casi exclusivo de los personajes principales implica además que, para el espectador, dado el enfoque subjetivo sobre el protagonista que el director toma, no pocos personajes secundarios acaban estando rodeados 
de un halo de misterio en cuanto a sus sentimientos y emociones, especialmente aquellos que se encuentran en medio de una relación afectiva con el protagonista, no habiendo tanta diferencia entre las incógnitas que levanta la pareja de Geni en Todos queremos lo mejor para ella, a la que sólo seguimos una vez la protagonista ha desaparecido, con la novia del joven protagonista en La mujer del aviador (La femme de l'aviateur, Eric Rohmer, 1981) dirigida por el cineasta francés en 1981. Este desconocimiento sobre las motivaciones y sentimientos de estos personajes, pues de ellos sólo sabemos lo que nos dejan entrever unos pocos minutos, provoca por desconocimiento de sus razones una oposición directa con los personajes principales, inmersos, recordemos, en complejos procesos de cambio y transformación. Si bien es cierto que los de Rohmer no parten habitualmente de actos tan violentos e incluso imprevisibles como los de Coll, siendo a menudo el cambio la consecuencia de la elección de un personaje por un periodo tranquilo de relax y meditación, tal y como sucede en La coleccionista (La Collectionneuse, Eric Rohmer, 1967) o en Cuento de verano (Conte d'été, Eric Rohmer, 1996). En todo caso, el relato es creado por las heroínas de Rohmer (Vilaró I Moncasí, 2016, p. 232)

Profundizando en esta necesidad de cambio, a veces voluntario, a veces involuntario, lo que los universos de ambos directores plantean con cierto optimismo es la concesión al tiempo como agente renovador y sanador, que acabará solucionando los problemas de hoy en un futuro en el que no serán más que recuerdos del pasado en un juego dominado por el azar, que tan rápido provoca un accidente, como introduce a una nueva persona deseada. Reparaciones inmanentes que provoca una dimensión a la que los personajes tan solo pueden sustraerse dentro de los cortos periodos de tiempo que suelen protagonizar ambas filmografías. Tal y como sostiene el cineasta francés a propósito de la mencionada Cuento de verano en unas palabras que igualmente podrían valer para hablar de Todos queremos lo mejor para ella:

Cuando se cuenta una historia, se tiene la impresión de que ella es crucial, de que es el momento decisivo de la vida. Si alguien es desgraciado, lo será durante todo el tiempo, y si es feliz, lo mismo. Pero yo quería mostrar cosas que no comprometen el porvenir. Algo que no tiene ninguna importancia 
porque el tiempo va a cambiar el curso de los acontecimientos. En diez años, el personaje será diferente. Quería mostrar algo que escapa al contador de historias, ya sea cineasta o novelista. El cine no se presta a contar vidas (Heredero, Santamaría, 2010, p. 244-245).

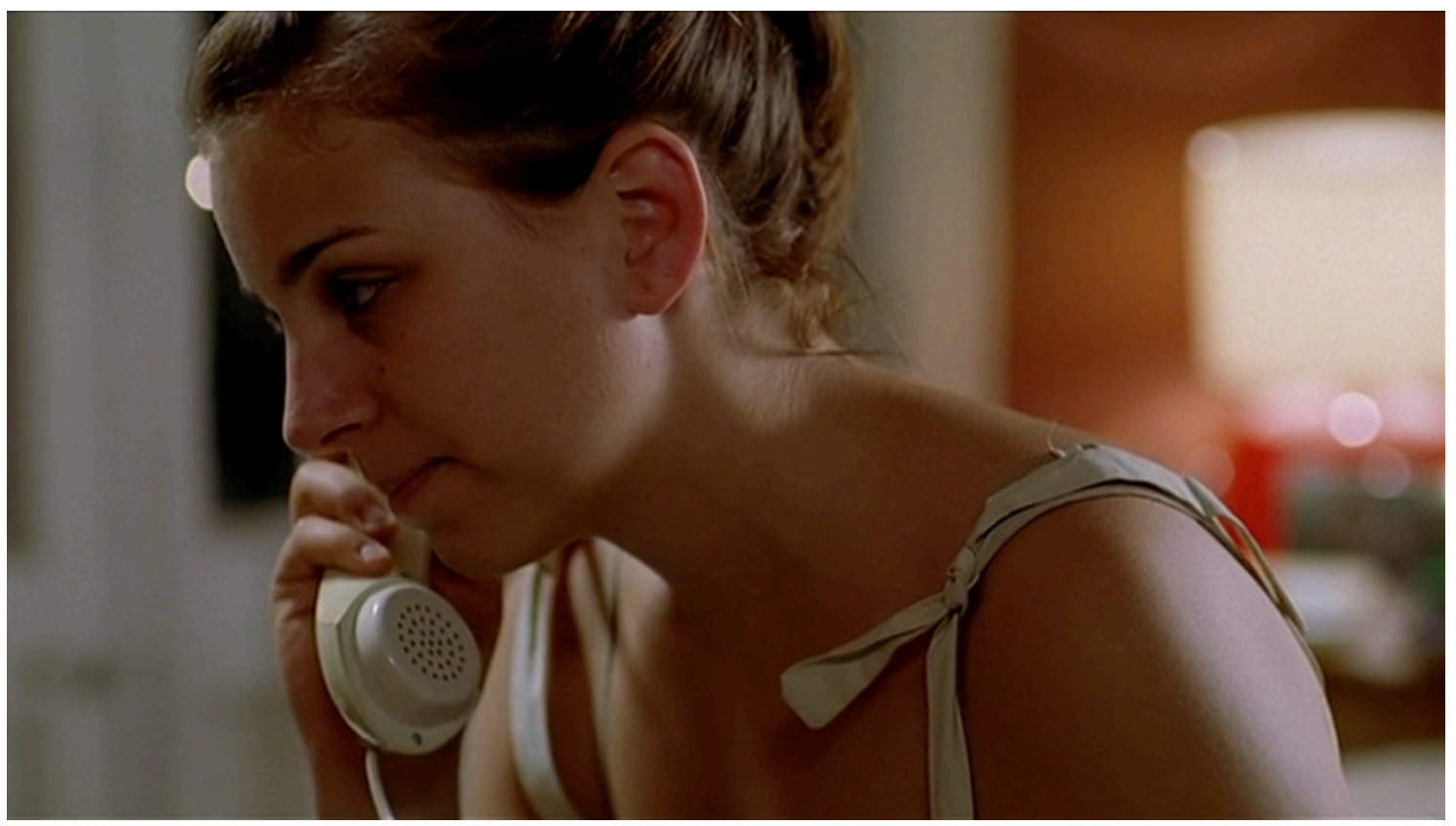

F3. Fotograma de Tres días con la familia (Mar Coll, 2009)

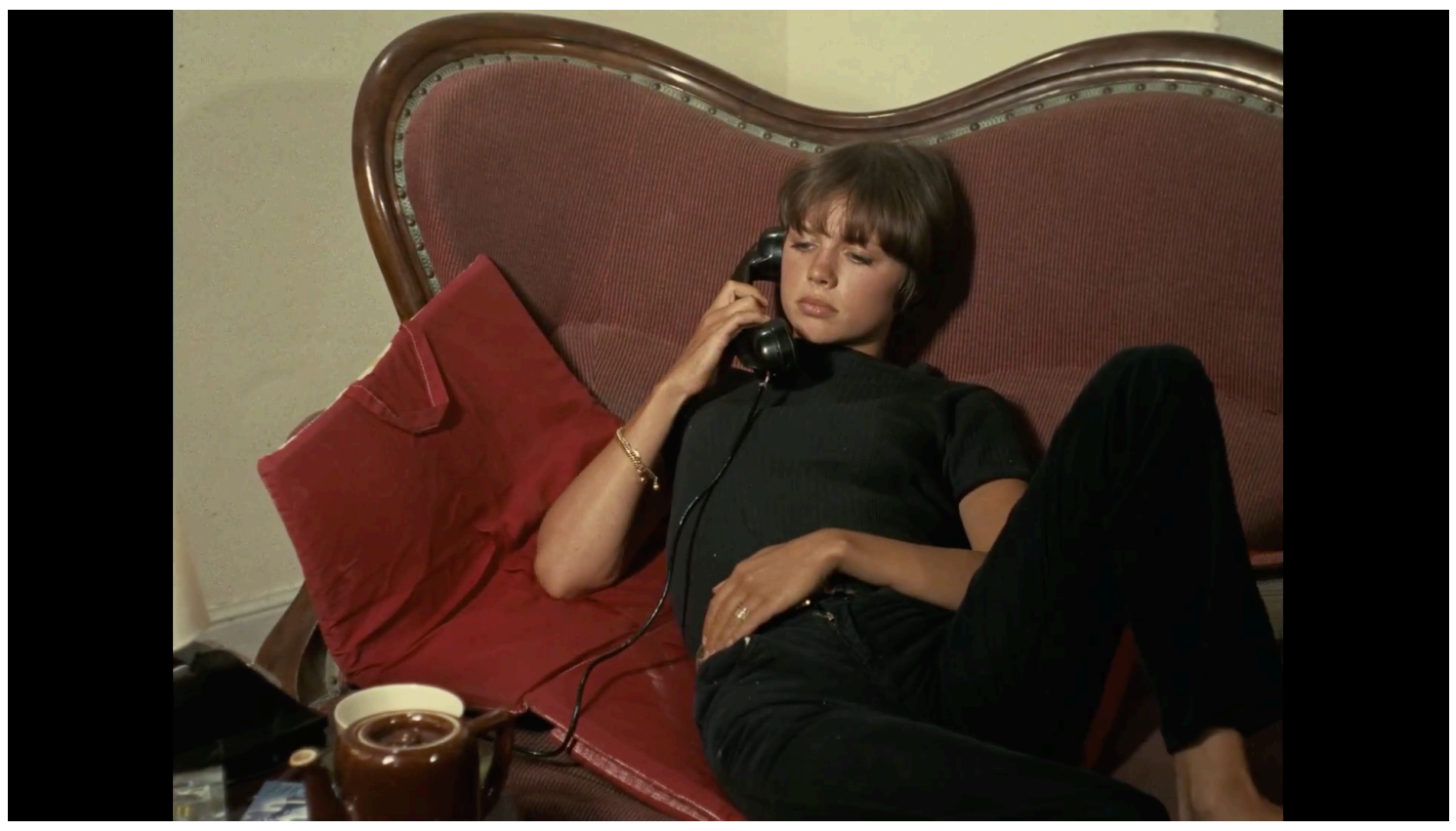

F4. Fotograma de La coleccionista (Eric Rohmer, 1967) 


\section{Creación de un estilo}

Decía el oscarizado director de fotografía Néstor Almendros de las planificaciones empleadas por Rohmer, con quien trabajó en más de una ocasión, que "Rohmer nunca se entrega a tiros 'humanamente' imposibles... Esto es casi un principio moral para él. Sus ángulos de cámara siempre tienen el punto de vista y están a la altura del ojo humano" (Almendros, 1984, p. 159)7. Así pues, lejos de ir en busca de la acción con complicados y técnicos movimientos de cámara, Rohmer prefiere partir de un estatismo neutro en el que graba el espacio en el que los personajes interaccionan con sí mismos o con los demás. Siguiendo a Keith Tester "En su mayor parte, las películas consisten en tomas largas cuidadosamente tomadas por cámaras que se encuentran en el nivel de los ojos de una persona que está de pie y que no está involucrada en la acción" (Tester, 2008, p. 2) ${ }^{8}$. La supuesta simpleza de planos que resulta de esta elección busca en realidad realizar un acompañamiento lo más naturalista y desapercibido posible de los personajes que protagonizan la acción. Siendo para ello clave la distancia con la que el cineasta filma a sus sujetos. Volviendo a las palabras Heredero y a Santamarina acerca del prolífico director francés:

La supuesta neutralidad de la mirada, a partir de este momento, es ya un concepto que empieza a desvanecerse. En primer lugar, por medio de la distancia (siempre muy calculada) que el director mantiene frente a sus personajes: una distancia que les permite desenvolverse con suficiente libertad sin que Rohmer se aleje artificialmente de ellos, y que- al mismo tiempo- posibilita al autor un acercamiento suficiente como para facilitar la aproximación necesaria, pero tampoco excesiva, del espectador, ya que no se pretende forzar, sino todo lo contrario, la identificación de éste con aquellos. [...] Rohmer se esfuerza por pasar inadvertido, rehuyendo todo encuadre que violente las formas armónicas, toda distorsión visual, toda mediación mecánica que no contribuya a clarificar o a capturar con nitidez lo que se tiene

\footnotetext{
7 Rohmer never indulges in "humanly" impossible shots ... This is almost a moral principle for him. His camera angles always have the point of view and are at the height of the human eye (Almendros, 1984, p. 159).

${ }^{8}$ For the most part the films consist of carefully composed long-takes shot by cameras that are at, or slightly below, the eye-level of a standing person who is not herself or himself involved in the action (Tester, 2008, p. 2).
} 
delante. Aquí la cámara es un instrumento de penetración y no de lucimiento. (Heredero, Santamaría, 2010, p. 96-97)

Palabras estas que igualmente podrían valernos para el cine de Mar Coll, quien precisamente por moverse sus narraciones en los parámetros de diálogos y silencios que se mencionaron en el apartado anterior, acaba optando por el mismo método de aproximación a sus sujetos. Lo cierto, es que al igual que le ocurre a Eric Rohmer, la manera de presentar los contenidos y temas que la cineasta catalana elige plasmar dentro de sus películas acaban determinando los aspectos formales y el estilo general que tienen estas. Funcionando la cámara como una suerte de amplificador que busca sacar a la luz todo lo que delatan pequeños gestos aparentemente banales, descartando movimientos invasivos hacia los sujetos que se pretende explorar y realizando una escasa, por no decir prácticamente inexistente, utilización de primeros planos o planos muy cerrados. Tal y como sostiene Gómez Tarín (2006, p. 116), "la cámara, en tanto que depositaria de la mirada, cumple una función de primer orden que no sólo es de mediación sino también de adjudicación." Dando espacio Coll a sus personajes, y alejándose de discursos parciales o interpretativos, sintetiza la cámara en su función objetiva, la cual se da "cuando aquello que se muestra parece ser visto desde un ente exterior a la narración, pero dentro del mismo universo verosímil." (Ibídem). De la misma forma que, al igual que para Rohmer, la cámara no es más que un instrumento para grabar todo aquello que se ponga delante (Tester, 2008, p. 12). O en palabras de Deleuze:

En Rohmer se trata, por una parte, de hacer de la cámara una conciencia formal ética capaz de ofrecer la imagen indirecta libre del neurótico mundo moderno (la serie de los Cuentos morales); por la otra, de arribar a un punto común del cine y de la literatura. (Deleuze, 1984, p. 115)

De esta manera, el cine de Mar Coll se dedica a mostrar espacios en el momento en el que estos se convierten en el centro de acción gracias a su ocupación por parte de los personajes de la obra o a los encuentros que estos mantienen en ellos. Predomina una intención claramente expositiva que acaba provocando una determinada identificación hacia el personaje que está 
presente en la mayoría de las secuencias y del que por lo tanto, el espectador tiene más conocimiento de su mundo interior.

Esta identificación también se produce gracias a los juegos de campocontracampo que emplea Coll de una manera más frecuente que Rohmer. El campo-contracampo, que al dividir el espacio de lo que se muestra en dos, requiere por lo general planos más cerrados que por lo tanto se acercan más al sujeto, delimita en su cine el espacio de la acción y la reacción.

La figura del campo-contracampo con raccord de mirada y ángulo aproximado al eje de la cámara, fue el último y más importante de los eslabones de la constitución del M.R.I. [Modo de Representación Institucional] como montaje dominante porque, a través de su utilización, el espectador queda inmerso en los diferentes cruces de miradas y en el interior del espacio diegético, base para la creación de una mecánica de identificación (Gómez Tarín, 2006, p. 128).
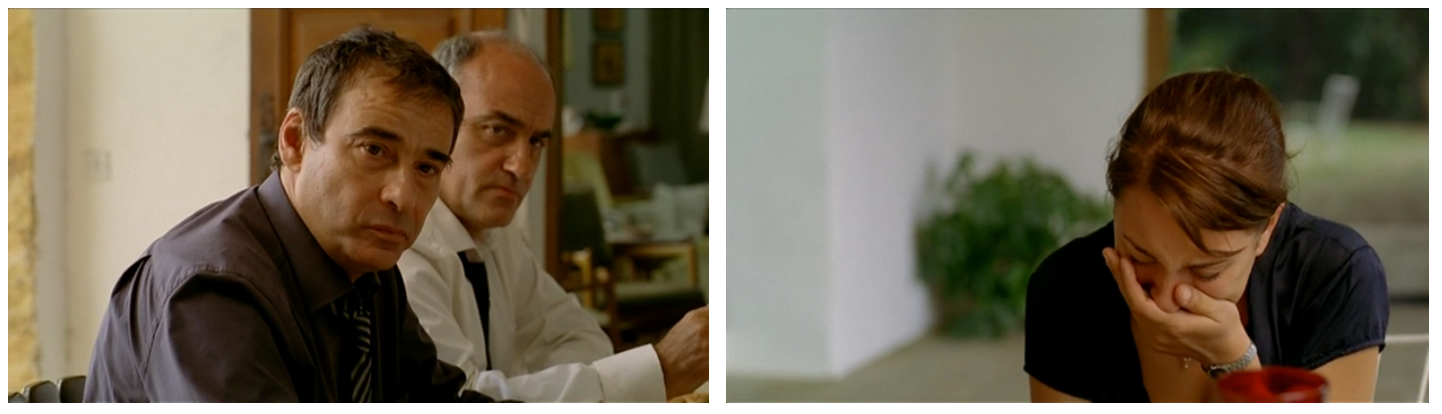

F5 y F6. Fotogramas de Tres días con la familia (Mar Coll, 2009)
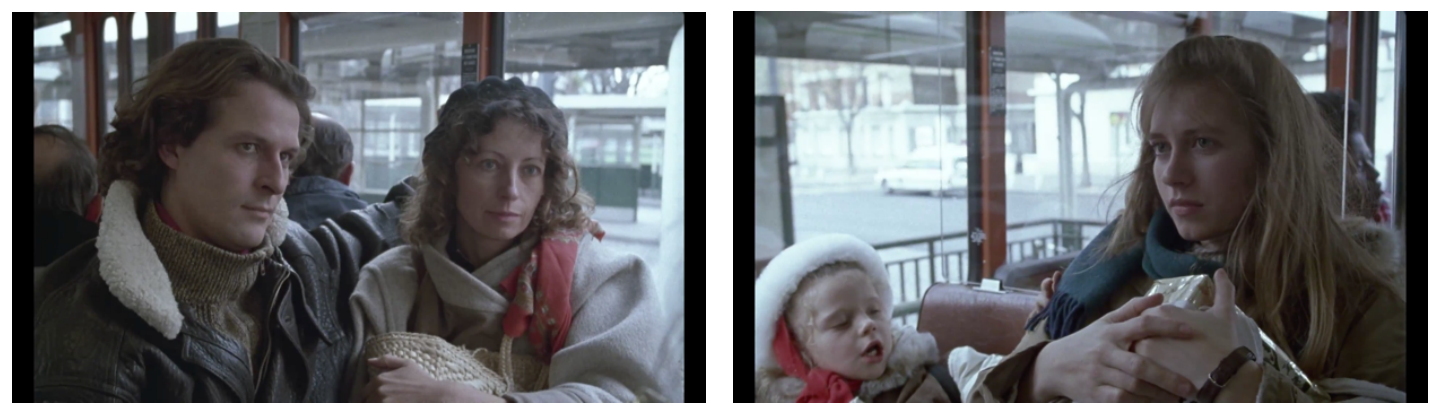

F7 y F8. Fotogramas de Cuento de Invierno (Eric Rohmer, 1992)

De igual manera, esta construcción narrativa que emana de un conjunto de escenas cerradas reduce el montaje a poco más que un ensamblaje de secuencias. Situándose quizás el único interrogante de las distintas opciones de montaje de una escena en los casos en los que la realizadora ha decidido 
fragmentar el espacio en un plano-contraplano, residiendo la dificultad de elección en la cuestión en torno a en qué momento pasar de la acción que realiza un personaje, a la reacción del otro.

En la búsqueda del máximo realismo, lejos de hacer variados juegos de edición, respeta Coll la duración de las tomas, aunque ello suponga reducir los efectos que una herramienta cinematográfica como el montaje puede proveer. Característica esta que de nuevo la aproxima al cine de Rohmer, en donde el habla de sus personajes se convierte en un elemento esencial de su cine más que en una forma de hacer avanzar la narración, y por ello debe de ser respetado. Contestaba el cineasta francés a una crítica al respecto de la gran cantidad de espacio concedido al habla de sus personajes en sus Cuentos Morales que el lenguaje, "Al igual que las imágenes es parte de la película que filmo." (Gunning, 2014, p. 30)9 Es en el acercamiento a este lenguaje, y a todos los elementos que su cine representa, en donde encuentra el profesor Tom Gunning la esencia del cine realista del francés, esencia que igualmente podría aplicarse a la cineasta catalana que aquí nos ocupa:

el cine no es un lenguaje; La película no es, como a menudo enfatiza, una forma de contar, sino una forma de mostrar. Como tal, es un medio que puede transmitir los diversos materiales del mundo, incluidos objetos, personas, árboles, rocas, océanos y partes del cuerpo, así como cuentos, conversaciones, filosofías e incluso obras de arte, mientras preserva su integridad individual e incluso ajena. El realismo cinematográfico no consiste en una simple verosimilitud o en hacer las cosas más vívidas o dramáticas; más bien, se trata de respetar el peso y la resistencia del lenguaje y de las cosas. (Gunning, 2014, p. 31$)^{10}$

\footnotetext{
9 Like the images it is part of the life I film (Gunning, 2014, p. 30).

${ }^{10}$ Cinema is not a language; film is not, as he often emphasizes, a way of telling, but a way of showing. As such, it is a medium that can convey the various materials of the worldincluding objects, people, trees, rocks, oceans, and parts of the body, as well as tales, conversations, philosophies, and even works of art-while preserving their individual and even alien integrity. Cinematic realism does not consist in simple verisimilitude or in making things more vivid or dramatic; rather, it is about respecting the weight and resistance of both language and things. (Gunning, 2014, p. 31)
} 


\section{Conclusiones}

De la presente comparativa entre el cine de Mar Coll y el de Eric Rohmer podemos extraer que el cine de la catalana se aproxima en sus temáticas al del realizador francés de la nouvelle vague. Es precisamente, debido a que la cineasta catalana busca realizar un retrato lo más naturalista y real posible de sus universos narrativos, que las formas cinematográficas que emplea son determinadas por el contenido de sus películas. Prescindiendo de trucos de montaje, manteniendo el plano el tiempo suficiente como para que la acción pueda desarrollarse en su integridad, y limitándose a filmar la realidad sin tomar el punto de vista de ningún personaje al descartar planos subjetivos, así como primeros planos y planos detalle que pudieran desvelar el artificio cinematográfico, cimienta Coll un estilo propio que acaba igualmente acercándose al estilo sobrio, en absoluto vanguardista, del cineasta francés.

Es gracias a la aplicación de sus planteamientos formales que se descubre que el cine de Coll hereda la concepción de cine de la palabra de Rohmer. Haciendo del lenguaje un elemento vertebrador presente en toda su filmografía que, lejos de verse relegado a un recurso que propicie el avance de la narrativa, se erige con total protagonismo dentro de esta. Al ser filmado como acto en sí, con la misma entidad de realidad que el resto de personajes, a los que acompaña en una evolución personal que es visible precisamente gracias a su presencia. Ayudando a construir un relato sólido que requiere, dados los silencios que le son propios a la palabra, que el espectador tome un rol activo en el desciframiento de la propia narrativa que se muestra ante sus ojos.

\section{Referencias bibliográficas}

Almendros, N. (1984). A Man with a Camera. Nueva York: Farrar Straus \& Giroux.

Cami-Vela, M. (2014). Directoras de cine en Cataluña: un recorrido histórico. Revista d'Estudis Catalans, 27, 27-45.

Cardullo, B. (2012). Interviews with Eric Rohmer. Gosport: Chaplin Books. 
Colaizzi, G. (2017). Mar Coll: Horizontes de Crisis. En Zurian, Francisco A. (Ed.), Miradas de Mujer. Cineastas españolas para el siglo XXI (pp. 109-122). Madrid: Editorial Fundamentos.

Cordero Sánchez L.P. (2017). María Ripoll: de Barcelona al mundo, un cine transnacional. En Zurian, Francisco A. (Ed.), Miradas de Mujer. Cineastas españolas para el siglo XXI (pp. 233-248). Madrid: Editorial Fundamentos.

Costa, J. (2009, 26 de junio). Una temprana madurez. Crítica de Tres días con la familia. El País. Recuperado de https://elpais.com/diario/2009/o6/26/cine/1245967211_850215.htm $\underline{1}$

Cousins, M. (2011). The Story of Film. Londres: Pavilion Books.

Deleuze, G. (1984). La imagen-movimiento. Barcelona: Paidós.

Entrevista a Mar Coll, directora de "Tres días con la familia” (2009, 2 de julio). Filmin. Recuperado de https://www.filmin.es/blog/entrevistaa-mar-coll-directora-de-tres-dias-con-la-familia

Gómez Tarín, F.J. (2006) El análisis del texto fílmico. Documento de la Universitat Jaume I. Recuperado de http://www.bocc.ubi.pt/pag/tarin-francisco-el-analisis-del-textofilmico.pdf

Gubern, R. (2014). Historia del cine. Barcelona: Anagrama.

Gunning, T. (2014) Eric Rohmer and the legacy of cinematic realism. En Anderst, L. (Ed.) The Films of Eric Rohmer. French New Wave to Old Master (pp.23-32). Nueva York: Palgrave Macmillan.

Heredero, C.F. (2014, 24 de marzo). Joyas perdidas del cine español. "Todos queremos lo mejor para ella” de Mar Coll. Caiman Cuadernos de Cine. Recuperado de https://www.caimanediciones.es/joyas-perdidas-delcine-espanol-todos-queremos-lo-mejor-para-ella-de-mar-coll/

Heredero, C.F. \& Santamaría, A. (2010). Eric Rohmer. Madrid: Ediciones Cátedra.

Leigh, J. (2012). The Cinema of Eric Rohmer: Irony, Imagination, and the Social World. Londres: Continuum.

Losilla, C. (2013) Emerge "otro" cine español. Un impulso colectivo. Caimán Cuadernos de Cine, 19, 6-8

Martín Sanz, A. (2013, 20 de octubre). Entrevista a Mar Coll, directora de “Todos queremos lo mejor para ella”. El antepenúltimo Mohicano. Recuperado de https://www.elantepenultimomohicano.com/2013/11/mar-collentrevista.html

Méndez-Leite, F. (2009, 17 de abril). Para los que todavía confíen en nuevas vías para el cine español. Crítica de "Tres días con la familia." Fotogramas. Recuperado de http://www.fotogramas.es/Peliculas/Tres-dias-con-la-familia\#critFG 
Monterde, J. E. (2004). Prólogo. La Nouvelle Vague a modo de balance. En La Nouvelle Vague. Sus protagonistas. (pp.9-22). Barcelona: Paidós.

Otero, I. (2017). Ellas: mujeres en el cine independiente español (3). Mar Coll abriendo el camino. Rinconete. Recuperado de https://cvc.cervantes.es/el_rinconete/anteriores/julio_17/10072017 01.htm

Ribes, F. (2013, 14 de octubre). Mar Coll: "Mi primera película miraba hacia atrás, esta mira hacia adelante”. Barcelonés. Recuperado de http://barcelones.com/cultura/mar-coll-mi-primera-pelicula-mirabahacia-atras-esta-mira-hacia-adelante/2013/10

Rohmer, E. (2000). El gusto por la belleza. Barcelona: Paidós.

Sontag, S. (2011). Sobre la fotografía. Barcelona: De bolsillo.

Tester, K. (2008). Eric Rohmer. Film as theology. Hampshire: Palgrave Macmillan.

Truffaut, F. (2007). Les films de ma vie. París: Champs arts.

Vilaró I Moncaisí, A. (2016). Entre la representación y la figuración. El cine de la Nouvelle Vague: una revisión histórica. Historia y Comunicación Social, 1 (21), 221-239.

Zurian, F. A. \& Pérez Sañudo, D. \& Vázquez Rodríguez, L. El falso boom de las mujeres directoras realizadoras españolas con un solo largometraje de ficción (2000-2015). En Zurian, Francisco A. (Ed.), Miradas de Mujer. Cineastas españolas para el siglo XXI (pp. 21-38). Madrid: Editorial Fundamentos. 